\title{
Neuromuscular and vascular hamartoma of the small intestine: is it Crohn's disease?
}

\author{
N A SHEPHERD AND J R JASS \\ From the Department of Pathology, St Mark's Hospital, City Road, London
}

SUMmARY Neuromuscular and vascular hamartoma has been described as a specific, if rare, stricturing condition of the small intestine. In this paper four cases with very similar macroscopic and histological features to those described as 'neuromuscular and vascular hamartoma' are presented. In three of the patients there was an earlier histologically proven diagnosis of Crohn's disease of the small intestine. We believe that 'neuromuscular and vascular hamartoma' is not a hamartomatous condition but may be seen as part of the histological spectrum of Crohn's disease, possibly in a chronic and 'burnt out' phase. Indeed the presence of these changes may provide additional evidence for the diagnosis of Crohn's disease.

In 1982 Fernando and McGovern reported two cases of a previously undescribed small intestinal condition called 'neuromuscular and vascular hamartoma'.' The two female patients presented with intestinal obstruction and stricturing lesions were found in the small bowel. Histological examination revealed mucosal ulceration and a widened submucosa, which contained aberrant fascicles of muscle derived from the muscularis mucosae, bundles of non-myelinated nerve fibres with scattered ganglion cells and numerous blood vessels. They had considered ischaemia as a possible cause, for ischaemic enteritis produces multiple concentric strictures with hyperplasia of the muscularis mucosae and incorporation of ganglion cells, but reasoned that the absence of fibrosis of the muscularis propria made this diagnosis very unlikely. The authors therefore interpreted the findings as a hamartomatous condition.

Smith, Filipe and Owen ${ }^{2}$ reported a single case of 'neuromuscular and vascular hamartoma', with very similar macroscopic and histological features as the two cases reported by Fernando and McGovern. There were additional pathological features such as mucosal cobblestoning, pyloric metaplasia and granulomas in local lymph nodes, producing a patho-

Address for correspondence: Dr N A Shepherd. Department of Pathology, St Mark`s Hospital, City Road. London ECIV 2PS.

Received for publication 4 June 1987 logical appearance mimicking Crohn's disease. The clinical features of the presentation had been strongly suggestive of Crohn's disease.

In this paper four cases with very similar macroscopic and histological features as 'neuromuscular and vascular hamartoma' are presented. In three of the cases, however, a previous clinical and pathological diagnosis of Crohn's disease had been made and this paper presents evidence which strongly suggests that 'neuromuscular and vascular hamartoma' is not a hamartomatous condition but it is an unusual histological consequence of inflammatory bowel disease, predominantly Crohn's disease.

\section{Case histories}

CASE 1

A 34 year old Caucasian woman presented with a one year history of central abdominal pain, vomiting and occasional diarrhoea. Three years before a right hemicolectomy had been carried out for small bowel obstruction. Crohn's disease had been diagnosed in her younger brother at the age of 23 . An explorative laparotomy revealed five discrete $2 \mathrm{~cm}$ long strictures, with some proximal dilatation, in both the jejunum and the ileum. The ileocolic anastomosis appeared normal. Each stricture was resected and end-to-end anastomoses carried out. Macroscopic examination 


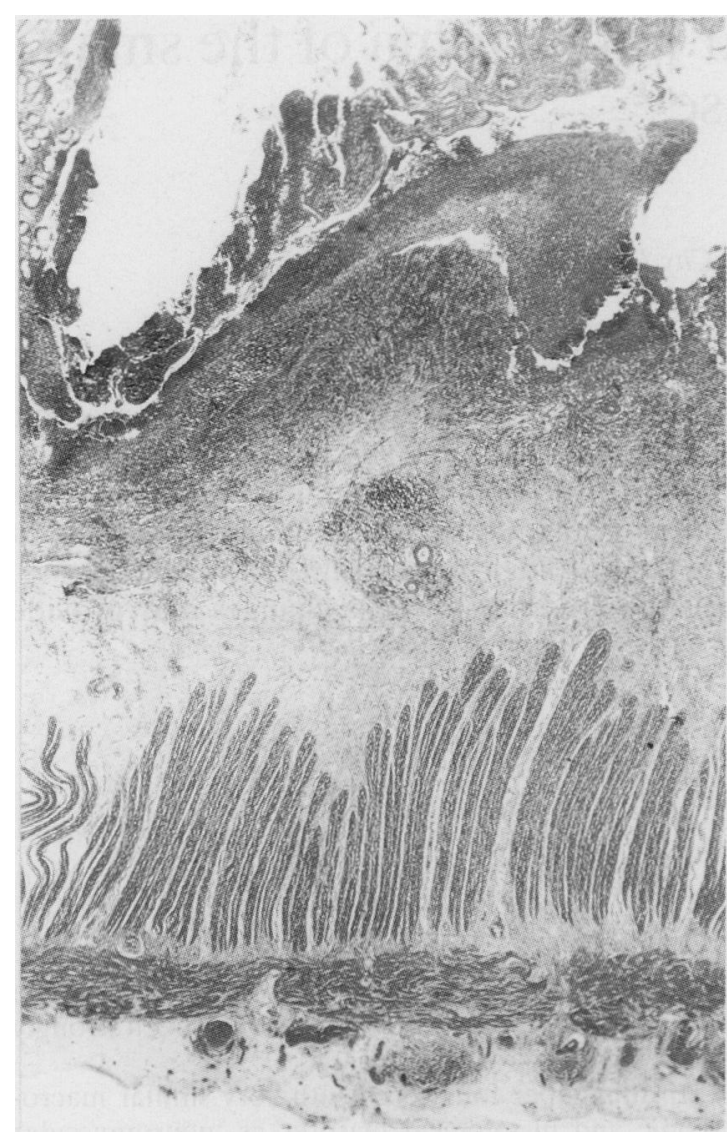

Fig. 1 Case 1. Right hemicolectomy specimen. There is fissuring ulceration and transmural inflammation in the form of lymphoid aggregates. $(H \& E)$

revealed five strictured segments of small intestine, measuring from $4.5 \mathrm{~cm}$ to $2.2 \mathrm{~cm}$ long. There was focal mucosal ulceration and cobblestoning.

Histological sections taken from the right hemicolectomy specimen were reviewed. There was focal but extensive surface ulceration with fissuring ulceration and pyloric metaplasia was seen in the adjacent mucosa. Transmural inflammation in the form of lymphoid aggregates was present but there were no granulomas (Fig. 1). There was neuronal hyperplasia, an apparent excess of ganglia and fibrosis with smooth muscle proliferation associated with the transmural inflammation. Numerous thin and thick walled arteries and veins were present in the submucosa. The histological features were those of Crohn's disease.

The histological features of the five strictured small intestinal segments are tabulated in the Table and are shown in Figure 2. There were very occasional lymphoid aggregates in the submucosa adjacent to

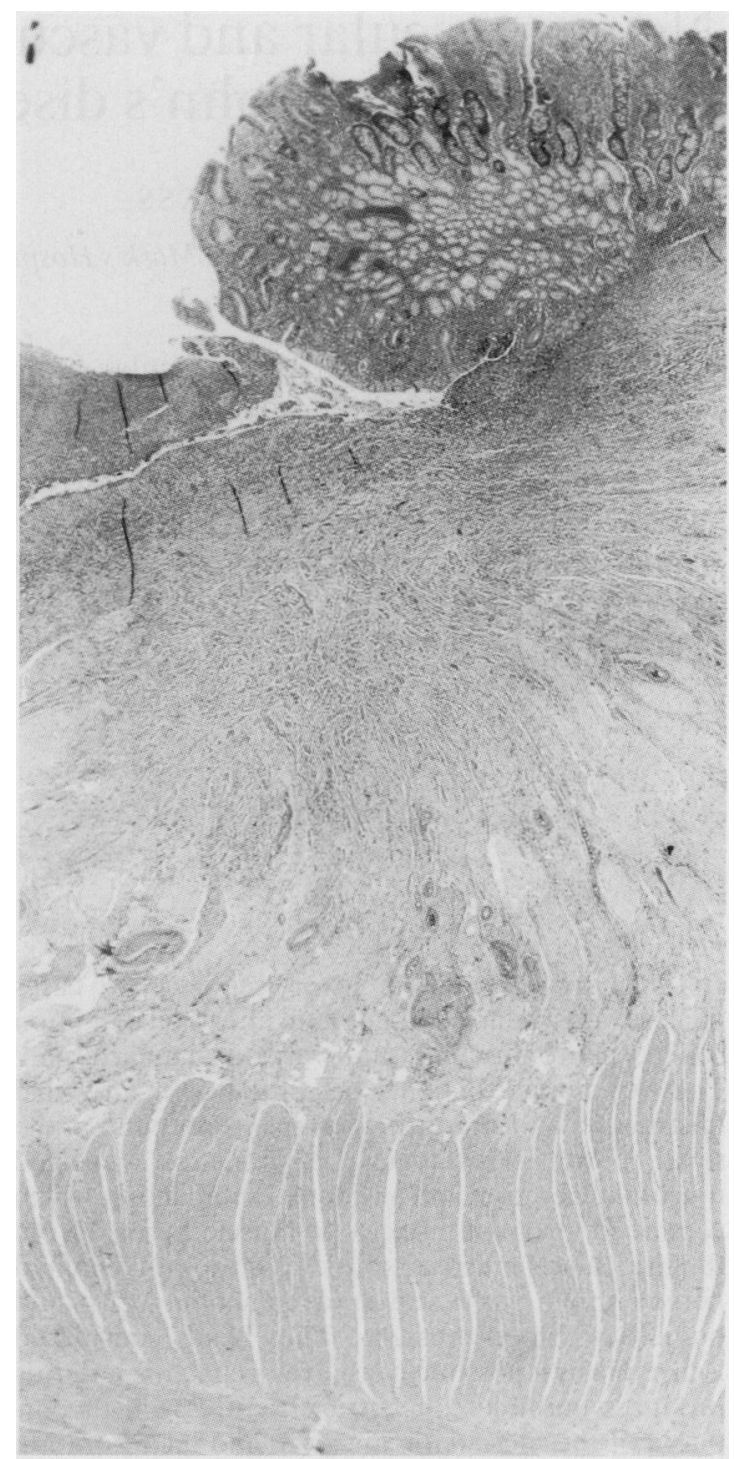

Fig. 2 Case 1. Section from one small bowel stricture. There is surface ulceration with pyloric metaplasia of the adjacent mucosa. Upper submucosa contains abundant smooth muscle and hyperplastic nerve fibres and thick walled veins are prominent in the deep submucosa. There is no transmural inflammation. $(H \& E)$

areas of inflammation, but there was no transmural inflammation. A single poorly formed granuloma with foreign body type giant cells was present in the serosa of one of the strictured segments.

CASE 2

A 58 year old Caucasian man presented with an 18 month history of discontinuous abdominal pain and 


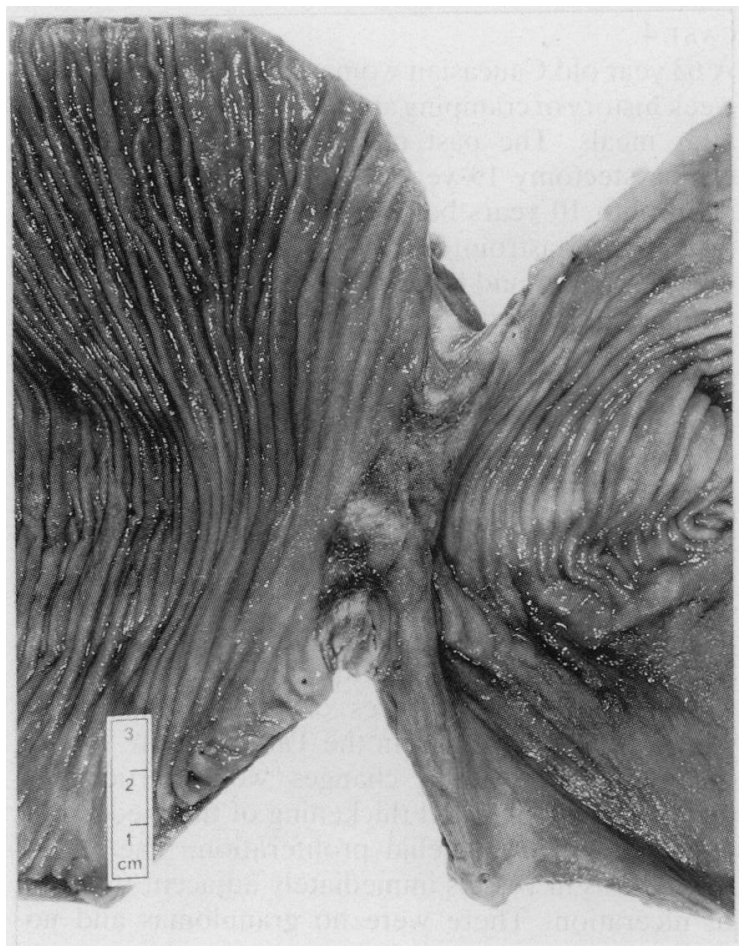

Fig. 3 Case 2. Proximal stricture of small intestine. There is ulceration at the stricture but the adjacent intestine appears normal.

distension, associated with diarrhoea. He had had six previous abdominal operations for small intestinal obstruction. A clinical and histological diagnosis of Crohn's disease had previously been made, but the histology was not available for review. A small bowel enema revealed a stricture of the terminal ileum with progressive dilatation of the proximal small intestine. Two strictures were discovered at laparotomy. Brown discoloration of the bowel was noted. A $29 \mathrm{~cm}$ segment of small intestine, including an ileocolic anastomosis was resected. Macroscopic examination of the specimen revealed two strictures, one at the ileocolic anastomosis and a second stricture of the ileum $19 \mathrm{~cm}$ proximal to this. There was ulceration of the mucosa at the proximal stricture (Fig. 3). On sectioning the bowel, there was a deep brown discoloration of the muscularis propria. The histological features of the strictured segments are presented in the Table. Figure 4 shows the mucosal ulceration with marked neuronal hyperplasia, smooth muscle proliferation and thick walled veins. In addition the muscularis propria and the muscle of submucosal arterioles showed extensive lipofuscinosis, indicative of the bowel brown syndrome.
Table

\begin{tabular}{|c|c|c|c|c|}
\hline & Case 1 & Case 2 & Case 3 & Case 4 \\
\hline Specimen & $\begin{array}{l}\text { Small bowel } \\
\text { strictures }\end{array}$ & $\begin{array}{c}\text { Ileal } \\
\text { stricture }\end{array}$ & $\begin{array}{c}\text { Ileocolic } \\
\text { anastomosis }\end{array}$ & $\begin{array}{c}\text { Ileal } \\
\text { strictures }\end{array}$ \\
\hline Granulomas & $+1-$ & + & - & - \\
\hline $\begin{array}{l}\text { Transmural } \\
\text { inflammation } \\
\text { Ulceration }\end{array}$ & - & - & - & $+1-$ \\
\hline Focal superficial & + & + & ++ & + \\
\hline Fissuring & - & - & + & - \\
\hline \multicolumn{5}{|l|}{$\begin{array}{l}\text { Neuronal } \\
\text { hyperplasia }\end{array}$} \\
\hline Nerve fibres & ++ & ++ & ++ & ++ \\
\hline Ganglia & ++ & ++ & + & ++ \\
\hline $\begin{array}{l}\text { Muscularisation } \\
\text { of submucosa } \\
\text { Vascular changes }\end{array}$ & ++ & $+t$ & ++ & ++ \\
\hline \multicolumn{5}{|l|}{$\begin{array}{l}\text { Vascular changes } \\
\text { Arteries } \\
\text { Veins* } \\
\text { submucosa }\end{array}$} \\
\hline submucosa & ++ & ++ & + & + \\
\hline serosa & - & ++ & - & ++ \\
\hline
\end{tabular}

MH $=$ medial hypertrophy: AEP $=$ asymmetrical endothelial proliferation: ${ }^{*}$ venous changes were irregular muscular thickening and ectasia.

CASE 3

A 73 year old Caucasian woman presented with recurrent episodes of colicky abdominal pain. Fourteen years before a right hemicolectomy had been performed for ileal stricturing and she had undergone an Ivalon rectopexy for complete rectal prolapse 18 months before. A laparotomy was carried out and a stricture of the ileocolic anastomosis was resected. Pathological examination revealed a segment of ileum $50 \mathrm{~cm}$ long anastomosed to $8 \mathrm{~cm}$ of colon. There were occasional aphthoid ulcers of the

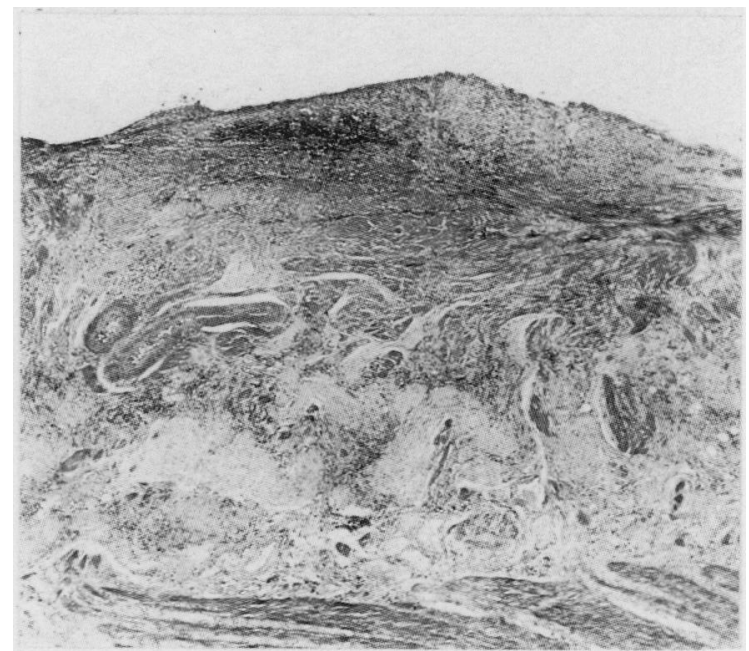

Fig. 4 Case 2. Section of stricture shown in Fig. 3. There is ulceration with marked neuronal hyperplasia, smooth muscle proliferation and thick walled veins. $(H \& E)$ 
mucosa in the proximal ileum. The distal $12 \mathrm{~cm}$ of ileum up to the anastomosis showed stricturing, bowel wall thickening and serpiginous ulceration.

Review of the histological sections of the right hemicolectomy showed the features of Crohn's disease. There was focal ulceration without fissures and there was pyloric metaplasia of the adjacent mucosa. There was transmural inflammation in the form of lymphoid aggregates and a single perilymphatic granuloma was present in the serosa. Focal neuronal hyperplasia was seen adjacent to areas of ulceration. Vascular changes included intimal proliferation of submucosal arterioles and ectasia of venules and capillaries. The proximal ileum contained typical aphthous ulcers. The histological features of the ileocolic anastomosis specimen are presented in the Table. The neuromuscular and vascular abnormalities were adjacent to areas of superficial ulceration but elsewhere there were fissuring ulcers and occasional lymphoid aggregates in the submocosa and serosa. There were no granulomas.

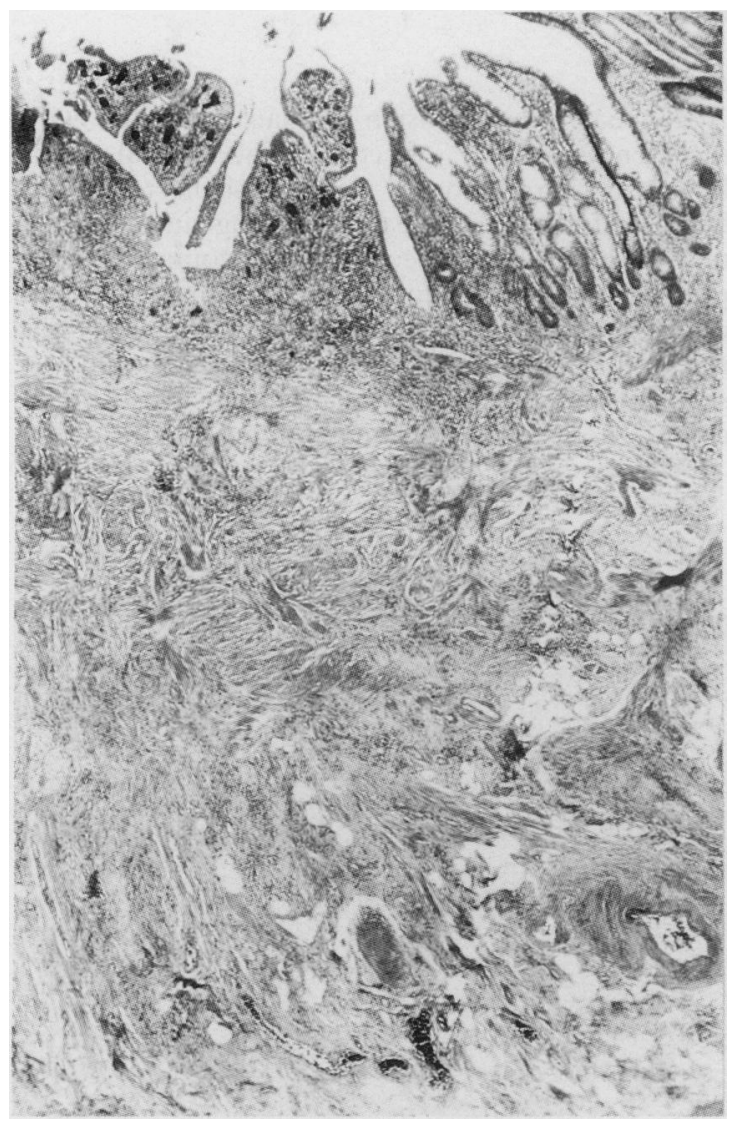

Fig. 5 Case 4. Section from small bowel stricture. There is focal ulceration with smooth muscle proliferation and thick walled veins in the submucosa. $(H \& E)$
CASE 4

A 63 year old Caucasian woman presented with a six week history of cramping abdominal pain particularly after meals. The past medical history included a cholecystectomy 19 years before and removal of a nephrolith 10 years before. There was no previous history of gastrointestinal disease apart from a duodenal ulcer and there had been no other surgical intervention. Barium studies showed a small bowel stricture with proximal dilatation. A $48 \mathrm{~cm}$ segment of ileum was resected at laparotomy. Pathological examination revealed three strictures of the ileum with focal ulceration. Since this operation, three years ago, there have been no further episodes of small intestinal obstruction although small bowel enema revealed some narrowing of the most distal ileum. Two years after her small bowel resection she developed lower back pain and the clinical features were suggestive of a sacroiliitis.

The histological features of the ileal resection specimen are presented in the Table and are shown in Figure 5. Arterial changes were particularly prominent and showed thickening of the media and asymmetrical endothelial proliferation. There was thrombosis in vessels immediately adjacent to areas of ulceration. There were no granulomas and no fissures were present.

\section{Discussion}

The pathological diagnosis of Crohn's disease rests on the evaluation of both macroscopic and microscopic features. The macroscopic appearances of small intestinal Crohn's disease are not entirely specific but include stricturing, serpiginous ulceration and cobblestoning of the mucous membrane." The histological features of Crohn's disease are equally variable. Granulomas and fissuring ulceration are the hallmarks of the disease but are not always present. Often the most useful sign is the presence of transmural inflammation in the form of lymphoid aggregates but, when these are scanty and there is no fissuring ulceration or granulomatous inflammation, the pathological diagnosis becomes more difficult. Fissuring ulceration and transmural inflammation are usually present in severe active Crohn's disease but the histological features of 'healed' Crohn's disease are unknown. It has been suggested that the presence of granulomas, some undergoing hyalinisation, in the absence of ulceration and significant inflammation, may represent a resolving phase of Crohn's disease, ${ }^{+}$ but these changes may be seen in macroscopically normal intestine adjacent to active Crohn's disease.

We have described four cases of small intestinal strictures and in three of the cases a diagnosis of Crohn's disease is unavoidable. In each case identical 
features to those described as 'neuromuscular and vascular hamartoma' have been present. All of the pathological features described in this condition may be seen in Crohn's disease. Neuronal hyperplasia is a relatively common accompaniment of small and large intestinal Crohn's disease. This includes both an increase in numbers of ganglion cells ${ }^{5}$ and enlargement of nerve trunks, ${ }^{6}$ which have been shown to contain greatly increased amounts of vasoactive intestinal polypeptide. ${ }^{7}$ Muscularisation of the submucosa is also not an unusual feature in the small intestine not only in Crohn's disease but also in ischaemic and radiation enteritis, and both of these conditions may be associated with neuronal hyperplasia and vascular changes. Although the bundles of smooth muscle are often in continuity with the overlying muscularis mucosae, the submucosal smooth muscle is not necessarily the result of proliferation of the muscularis mucosae but may be the result of muscularisation of a fibrotic submucosa, also a common feature of chronic stricturing diseases. Muscularisation of fibrotic tissues may be seen in other tissues, particularly in the lung in pulmonary fibrosis. ${ }^{8}$ Vascular changes are also described in Crohn's disease and these include degenerative arterial lesions, with duplication of the internal elastic lamina and medial hypertrophy, and irregular thickening of the walls of veins as a result of hyperplasia of fibrous, elastic and muscle tissue. ${ }^{9}$

We have recently reviewed 50 sequential cases of small intestinal Crohn's disease and, in many cases, histological features identical to those of 'neuromuscular and vascular hamartoma', namely neuronal hyperplasia and an excess of ganglia, aberrant bundles of smooth muscle, and thickened and ectatic arteries and veins, are not uncommon findings. These changes were associated with fissuring ulceration and transmural inflammation and therefore the diagnosis of Crohn's disease was not in doubt. In the four cases we have presented, the histological features present were not diagnostic although occasional granulomas were seen in cases 1 and 2 and there was fissuring ulceration in case 3. There was no transmural inflammation in the first three cases and patchy transmural inflammation in case 4 . The histology from the previous resections in cases 1 and 2 both showed the classical changes of Crohn's disease. In case 3 a previous clinical and pathological diagnosis of Crohn's disease had been made. The sections were not available for review but a history of six previous small intestinal resections is certainly much more like Crohn's disease than a hamartomatous condition.

In their paper Fernando and McGovern' make no mention of the presence or absence of inflammation and presumably no granulomas were present. One of their patients was Australian, a country with a high prevalence of Crohn's disease but the other patient was of Indonesian extraction. Crohn's disease is rare in eastern Asia and therefore it may be that another chronic stricturing disease of the small intestine, possibly tuberculosis or a parasitic infestation, is responsible. Smith et al describe mucosal cobblestoning of the strictured segment of small intestine and histologically there were granulomas present in the local lymph nodes, features which are certainly suggestive of Crohn's disease. An unusual feature in their case, and also in our case 4, was the presence of thrombosis in superficial blood vessels. In both cases the thrombosis was adjacent to areas of ulceration, however, and is therefore probably a secondary phenomenon. They describe abnormalities in all layers of the bowel but the pathology was predominantly mucosal and submucosal. The muscularis propria showed secondary hypertrophy, which may be seen in any stricturing condition and the serosa showed ectasia of blood vessels, a common accompaniment of active inflammatory bowel disease, particularly in an acute fulminating phase.

In conclusion we believe that 'neuromuscular and vascular hamartoma' is probably not a hamartomatous condition, for identical pathological features may be seen as part of the histological spectrum of Crohn's disease. The absence of fissuring ulceration and transmural inflammation in our four cases suggest that the pathological features may be those of a chronic, 'burnt out' form of the disease. We have, however, seen similar changes in both radiation and ischaemic enteritis, often with fibrosis of the muscularis propria. Therefore the neuromuscular and vascular abnormalities, in isolation, are a relatively non-specific change. In combination with either fissuring ulceration, transmural inflammation or granulomas, the changes may provide further histopathological evidence for a diagnosis of Crohn's disease.

We thank Dr B C Morson, to whom two of our cases were referred, for his help and encouragement and Ms Jill Maybee for photographic assistance.

\section{References}

1 Fernando SSE, McGovern VJ. Neuromuscular and vascular hamartoma of the small bowel. Gut 1982; 23: 1008-12.

2 Smith CET, Filipe MI, Owen WJ. Neuromuscular and vascular hamartoma of small bowel presenting as inflammatory bowel disease. Gut 1986; 27: 964-9.

3 Morson BC, Dawson IMP. Gastrointestinal pathology. Oxford: Blackwell Scientific Publications, 1979: 299.

4 Gray BK, Lockhart-Mummery HE, Morson BC. Crohn's disease of the anal region. Gut 1965; 6: 515-24.

5 Davis DR, Dockerty MB, Mayo CW. The myenteric 
plexus in regional enteritis: a study of ganglion cells in the ileum in 24 cases. Surg Gynecol Obstet 1955; 101: 208-16.

6 Whitehead R. Pathology of Crohn's disease. In: Kirsner JB, Shorter RG, eds. Inflammatory bowel disease. 2nd ed. Philadelphia: Lea \& Febiger, 1980: 296-307.

7 Bishop AE, Polak JM, Bryant MG, Bloom SR, Hamilton
S. Abnormalities of vasoactive intestinal polypeptidecontaining nerves in Crohn's disease. Gastroenterology 1980; 79: 853-60.

8 Spencer H. Pathology of the lung. 4th ed. Oxford: Pergamon Press, 1985: 797.

9 Morson BC, Dawson IMP. Gastro-intestinal pathology. Oxford: Blackwell Scientific Publications, 1979: 304. 